\title{
Mulheres das águas: comunidade, gênero e raça
}

Women of the waters: community, gender and race

Mujeres de las aguas: comunidade, género y raza

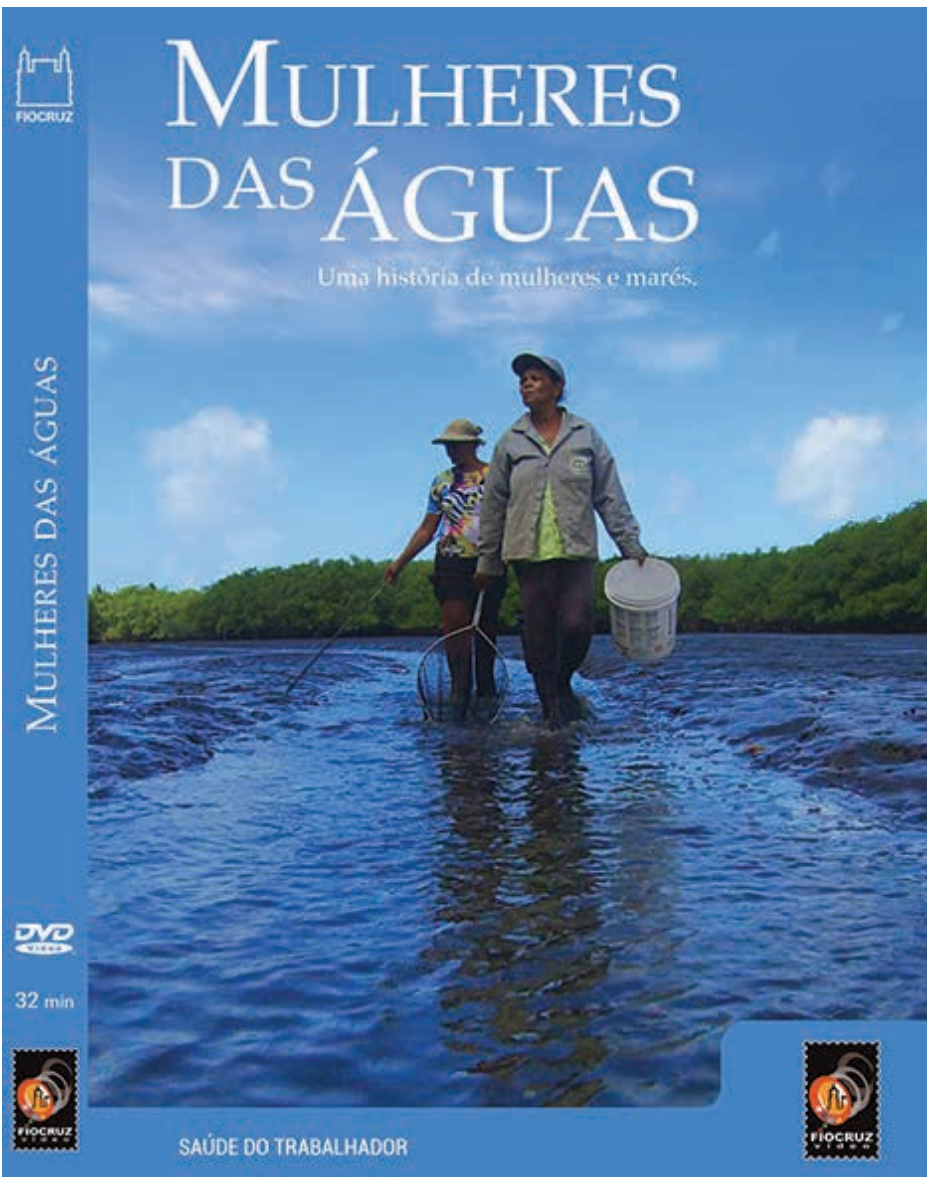




\section{Resumo}

O documentário 'Mulheres das águas' retrata a vida e as lutas de pescadoras nos manguezais do Nordeste do Brasil. O modo de vida e a sobrevivência de suas famílias estão ameaçados pela poluição provocada pelas grandes indústrias e pelo turismo predatório que causam danos ao ecossistema dos manguezais, onde inúmeras espécies marinhas se reproduzem. Nesta resenha, a produção é analisada na perspectiva dos debates sobre relações raciais, gênero, senso de comunidade e condições de trabalho. No bojo do documentário, há o engajamento de trabalhadoras em prol da preservação dos territórios pesqueiros, onde se concentra a principal atividade econômica das comunidades a que pertencem.

Palavras-chave: Comunicação; Meio ambiente; Saúde do trabalhador; Gênero; Raça; Direitos sociais; Direitos humanos.

\section{Abstract}

The documentary 'Women of the waters' tells the life and struggles of fishers in the mangrove swamps of northeastern Brazil. The way of life and the survival of their families are threatened by pollution caused by large industries and the predatory tourism that cause damage to the mangrove ecosystem, where numerous marine species reproduce. In this review, the production is analyzed from the perspective of the debates about race relations, gender, sense of community and working conditions. Furthermore, the documentary shows the engagement of theses workers for the sake of preservation of fishery territories, where the main economic activity in the communities to which they belong is concentrated.

Keywords: Communication; Environment, Worker's health; Gender; Race; Social rights; Human rights.

\section{Resumen}

El documental 'Mujeres de las aguas' retrata la vida y la lucha de las pescadoras en los manglares del nordeste de Brasil. La forma de vida y la supervivencia de sus familias son amenazadas por la contaminación causada por las grandes industrias y el turismo depredador que dañan el ecosistema de manglar, donde se reproducen numerosas especies marinas. En esta reseña, la producción se analiza en la perspectiva de los debates sobre relaciones de raza, género, sentido de comunidad y de las condiciones de trabajo. En el seno del documental, hay el compromiso de las trabajadoras con la preservación de los territorios de pesca, donde se concentra la principal actividad económica de las comunidades a las que pertenecen.

Palabras clave: Comunicación; Medio ambiente; Salud del trabajador; Género; Raza; Derechos sociales; Derechos humanos.

Ficha técnica da obra resenhada:

Título: Mulheres das águas.

Direção: Beto Novaes.

Produção: VideoSaúde Distribuidora e UFRJ.

Distribuição: VideoSaúde Distribuidora.

Data: 17 jan. 2017.

Duração: 32m25s.

Disponível em: https://www.youtube.com/watch?v=P62sFliw7K8

Acesso em: 28 maio 2019.

Declaração de conflito de interesses: não há.

Agradecimentos/Contribuições adicionais: não há.

Histórico do artigo: submetido: 24 abr. 2019 | aceito: 28 maio 2019 | publicado: 28 jun. 2019.

Apresentação anterior: não houve.

Licença CC BY-NC atribuição não comercial. Com essa licença é permitido acessar, baixar (download), copiar, imprimir, compartilhar, reutilizar e distribuir os artigos, desde que para uso não comercial e com a citação da fonte, conferindo os devidos créditos de autoria e menção à Reciis. Nesses casos, nenhuma permissão é necessária por parte dos autores ou dos editores. 
Odocumentário ‘Mulheres das águas’ aborda o cotidiano de pescadoras dos manguezais no Nordeste brasileiro e tem inspirado debates sobre relações raciais, gênero, condições de trabalho e manutenção dos ecossistemas país afora. A película também traz em seu bojo o engajamento de trabalhadoras em prol da preservação dos territórios pesqueiros, onde se concentra a principal atividade econômica das comunidades a que pertencem.

Os mangues e coroas têm sido alvos de degradação por meio da ação desenfreada das corporações, da especulação imobiliária e do turismo predatório que avança sobre essas regiões. Entre os relatos que atravessam o filme de Beto Novaes, os vazamentos de petróleo e o assoreamento de mangues para a expansão da monocultura, a fim de atender as demandas do agronegócio, tornaram-se recorrentes nos manguezais da Bahia e de Pernambuco, estados recortados pelo documentário.

O uso indiscriminado de agrotóxicos para fomentar a agricultura e o lixo tóxico gerado pelas indústrias, uma vez absorvidos pelo solo e pela água, matam nascentes de rios e todo um ecossistema marinho e, por consequência, interferem diretamente na vida das pessoas que vivem nos arredores desses manguezais e coroas.

'Mulheres das águas' apresenta-se como um manifesto de pescadoras a partir daquilo que lhes é comum no cotidiano. Pelo direito à manutenção do ofício da pesca artesanal no interior de suas comunidades, elas têm desafiado um modelo de Estado - inclinado a atender as demandas do mercado -, o poder econômico das grandes corporações e um sistema no qual o machismo e o racismo estrutural dão as cartas.

Segundo Muniz Sodré1, ao mesmo tempo em que a elaboração do comum tem sido presidida pelo mercado e administrado pelas corporações para o espraiamento da ideologia financeira, o comum também é reforçado por sua riqueza simbólica no interior da comunidade. Por essa razão, entrar na disputa capitalista e dominá-lo por completo é dominar a comunicação, e para que a comunicação aconteça é essencial que haja comunidade, vinculação e comum.

É, por fim, na direção da diversidade que se edifica uma ciência da comunicação humana, “desde o vínculo coesivo do comum até as relações em voga que, por sua vez, dão margem às formas crescentes de ativismo coletivo com vistas à recomposição do laço simbólico que subjaz a formação social” ${ }^{\text {"1 }}$. 187) de um grupo que convive num espaço.

Mesmo com o avanço do neoliberalismo, um fenômeno global cuja lógica capitalista se estabelece a partir de um Estado mínimo, regulador e facilitador da ação do mercado em detrimento do bem-estar social estatal, o documentário apresenta-se como um instrumento de resistência local pela garantia de direitos sociais e previdenciários dessas operárias. Nesse sentido, a experiência do audiovisual como instrumento legitimador de narrativas que são preteridas nos grandes conglomerados midiáticos inscreve o documentário no campo das insurgências contra um sistema perverso, sexista e racista.

As contranarrativas ali contidas potencializam uma espécie de levante a partir das vozes dessas pescadoras, inseridas num universo pautado pela desigualdade, precariedade das condições de trabalho e escassez de direitos sociais. Em exemplo similar ${ }^{2}$, os ronderos de Cajamarca, nativos de um pequeno povoado peruano, mobilizaram-se por meio de canções que desafiaram o establishment local e disseram não à atuação predatória de multinacionais mineradoras. A expansão da atividade de extração de ouro naquela região traria danos irreversíveis ao ecossistema e comprometeria a sobrevivência de gerações vindouras.

De acordo com Júlio Mendível $^{2}$, a música se apresenta como uma importante ferramenta de mediação, e também de sustentação, de lutas políticas e legitimação de protestos. Para o antropólogo, o repertório dos ronderos se constituiu como um elemento que potencializou as lutas e deu voz à população campesina, num claro e bem-sucedido enfrentamento ao poder econômico da mineradora e ao aparato midiático contra os movimentos de resistência à atividade da multinacional.

Ao mesmo tempo em que o mangue e as coroas aparecem como arena de disputa, o filme apresenta esses espaços de forma lírica e poética. Dessa forma, privilegia o elo sagrado que essas mulheres estabelecem com o lugar. Quando transformam esse território ameaçado pelo 'progresso' num ambiente onde as relações de pertinência, afeto e sororidade se fortalecem durante a jornada cotidiana, as marisqueiras formam uma comunidade que é organizacional e também da ordem do vínculo e do afeto. 


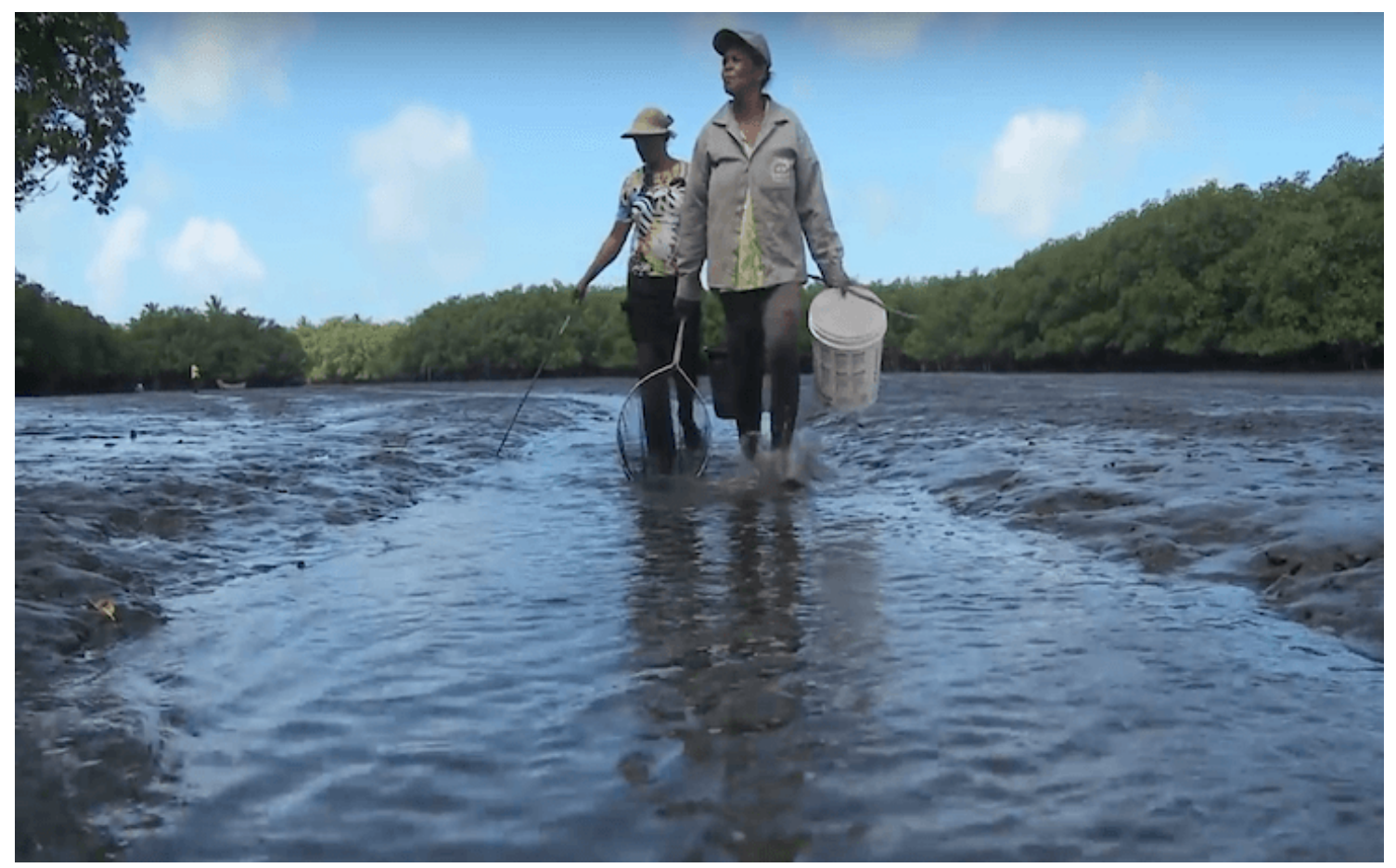

Figura 1 - Além de uma comunidade organizacional, as marisqueiras formam vínculos de pertencimento e afeto Fonte: Divulgação.

Segundo Raquel Paiva ${ }^{3}$, a comunidade não se constitui apenas como mera convivência em determinado espaço, e sim a partir da perspectiva do compartilhamento do comum ou de uma troca. A comunidade se dá na ordem física e também no virtual, na conectividade do sensório e sincronização das emoções, podendo produzir ou fortalecer um individualismo de massa, "visto que os indivíduos agrupados por interesses comuns podem retomar a possibilidade que lhes foi negada como cidadãos de interferir nas decisões do poder público”3 (p.53).

Embora pesquisas do Instituto Brasileiro de Geografia e Estatística (IBGE) registrem um crescimento expressivo do número de mulheres comandando domicílios no país desde a década de $1970^{4}$, além da crescente inserção delas no mercado de trabalho, a paridade de gênero na formalização do trabalho, remuneração e ocupação de cargos com poder de decisão ainda é uma realidade distante. As pescadoras dos manguezais e das coroas, embora sejam um braço importante na pesca em seus respectivos povoados, têm a precificação do que produzem diariamente avalizada por homens que, por sua vez, não dão o valor agregado ao trabalho que elas realizam.

Além da dupla jornada, o enfrentamento das desigualdades no mercado de trabalho, num cenário onde o comando ainda é majoritariamente masculino, essas trabalhadoras dos manguezais lutam para sair da invisibilidade e participar dos núcleos de decisão. O último estudo Estatísticas de Gênero: Indicadores Sociais do Brasil 5 , também divulgado pelo IBGE, aponta que as mulheres brasileiras ganham o equivalente a $75 \%$ do que os homens ganham, mesmo elas sendo maioria nos bancos universitários, no mercado de trabalho e na liderança de lares brasileiros.

Quando o recorte racial é feito, a disparidade é maior. Mulheres negras e pardas ganham $43 \%$ menos que homens e o acesso à educação, à saúde e às oportunidades em diferentes setores da sociedade esbarram no racismo estrutural que se reproduz nas condições de desigualdades. Nesse sentido, o conceito de lugar de fala, elaborado por Djamila Ribeiro ${ }^{6}$ contribui para a emancipação social por meio de vozes que historicamente foram excluídas e subalternizadas, ou seja, nunca ocuparam espaços de privilégio em que a fala é efetivamente ouvida.

Em concordância com a filósofa brasileira, o sujeito subalterno nas palavras de Spivak é aquele pertencente às "camadas mais baixas da sociedade constituídas pelos modos específicos de exclusão dos mercados, da representação política e legal, da possibilidade de se tornarem membros plenos no estatuto social dominante” (p.12). 
Quando mira no cotidiano de mulheres pescadoras dos manguezais e coroas da região Nordeste, 'Mulheres das águas' torna públicas pautas caras à contemporaneidade por se deslocarem do local para o universal sem prejuízo de leitura ou contextualização. Reconhecidos alguns avanços resultantes do engajamento de mulheres negras nos últimos anos, ainda há um longo caminho a percorrer neste novo século, no qual dar voz e espaço à diversidade ainda mostra-se como um espinhoso desafio.

Como afirma a filósofa estadunidense Angela Davis ${ }^{8}$, quando a mulher negra se movimenta, toda estrutura da sociedade se movimenta junto com ela. Derrubar o muro das desigualdades, enfrentar e resistir às opressões que regem a sociedade brasileira, sobretudo nas relações de trabalho e nos meios de produção, significa mover estruturas seculares. E 'Mulheres das águas' colabora de forma grandiosa na construção desse novo mundo.

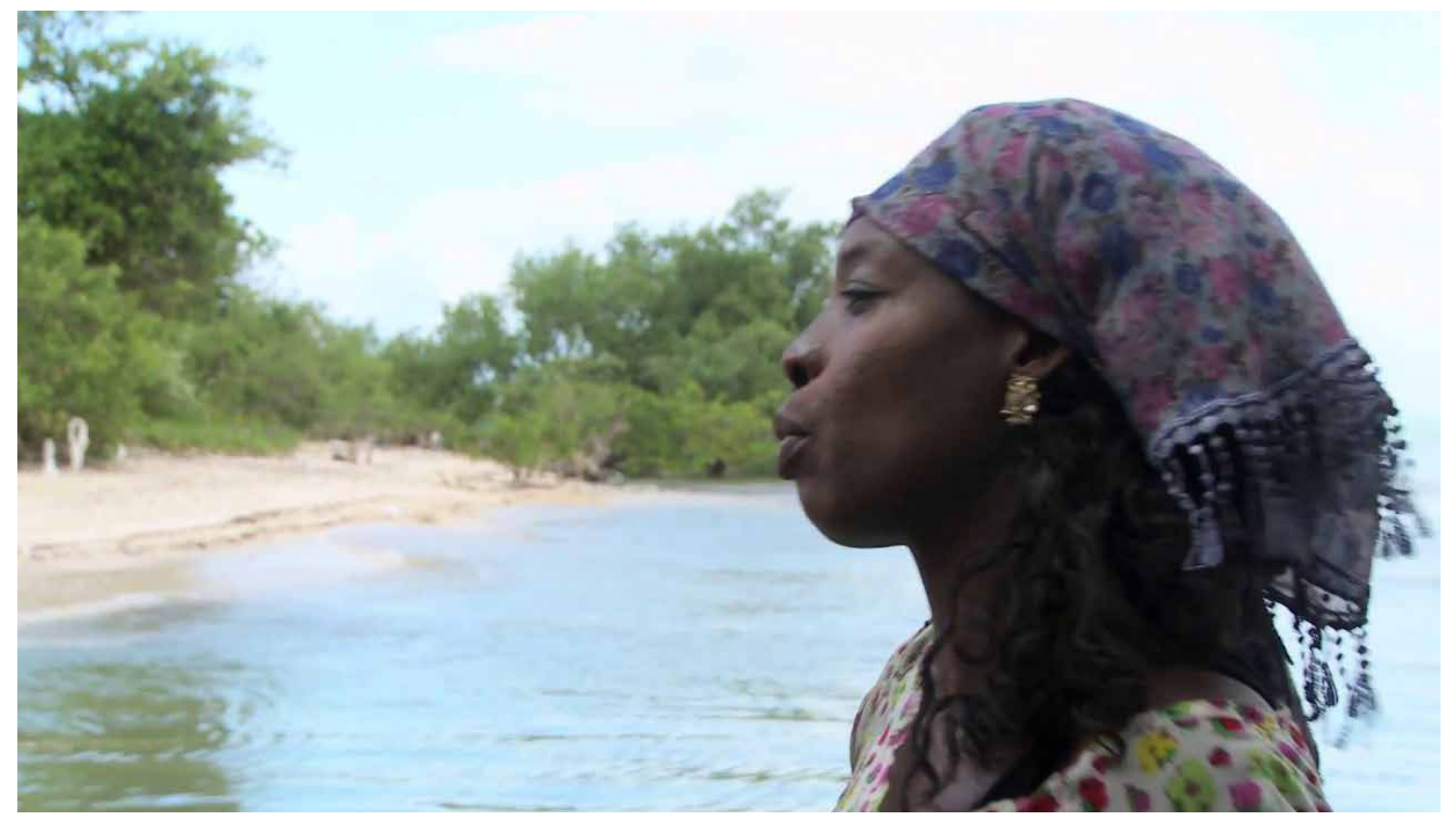

Figura 2 - A narrativa expressa o engajamento das mulheres negras em movimentos sociais na contemporaneidade Fonte: Divulgação.

\section{Referências}

1. Sodré M. A Ciência do comum: notas sobre o método comunicacional. Petrópolis: Vozes; 2014.

2. Mendível J. Singing for water, singing against gold: music and the politics of representation in the Peruvian Northern Andes. Trans. 2016;20:1-28.

3. Paiva R. O espírito comum: comunidade, mídia e globalismo. Rio de Janeiro: MAUAD; 2003.

4. IBGE. IBGE divulga indicadores sociais sobre a mulher [Internet]. 2002 [citado em 20 abr. 2019]. Disponível em: https://ww2.ibge.gov.br/home/presidencia/noticias/07032002mulher.shtm

5. IBGE. Estatísticas de gênero: indicadores sociais das mulheres no Brasil [Internet]. [2016] [citado em 20 abr. 2019]. Disponível em: https://www.ibge.gov.br/estatisticas/multidominio/genero/20163-estatisticasde-genero-indicadores-sociais-das-mulheres-no-brasil.html?=\&t=0-que-e

6. Ribeiro D. O que é lugar de fala?. Belo Horizonte: Letramento; 2017.

7. Spivak G. Pode o subalterno falar?. Belo Horizonte: Editora UFMG; 2010.

8. Alves A. Angela Davis: "Quando a mulher negra se movimenta, toda a estrutura da sociedade se movimenta com ela". El País [Internet]. 2017 [citado em 20 abr. 2019]. Disponível em: https://brasil. elpais.com/brasil/2017/07/27/politica/1501114503 610956.html 